\title{
Efectos Negativos del Turismo: Su papel como Vector de propagación del Covid- 19
}

\section{Neggative Effects of Tourism: its performance as a COVID-19 propagation vector.}

\section{Turismo, propagador del COVID-19}

\section{Laura Sofia Camacho Diaz. MMNT}

Universidad Juárez Autónoma de Tabasco, División Académica de Ciencias Económico Administrativas, Tabasco - México.

Contacto: 211B35006@alumno.ujat.mx

\section{Resumen}

El objetivo de este artículo es relacionar teóricamente el papel que ha tenido la actividad turística como vector propagador del covid-19. Se construyó bajo el enfoque de investigación exploratoria con la revisión de literatura existente que permitiera determinar cómo las concentraciones masivas contribuyeron al incremento de la curva de contagios. El documento sugiere interrogantes que permitan abrir el debate académico en torno al análisis de la necesidad contra la contingencia, específicamente respecto al peso de la economía contra el deber superior de preservar la vida de las personas.

Palabras clave: Turismo, pandemia, COVID-19, economía, vidas humanas.

\begin{abstract}
The objective of this article is to theoretically link the role that tourism activity has played as a propagating vector of covid-19. It was built under the exploratory research approach with the review of existing literature that allowed determining how the massive concentrations contributed to the increase in the contagion curve. The document suggests questions that allow to open the academic debate around the analysis of necessity against contingency, specifically regarding the weight of the economy against the superior duty of preserving people's lives
\end{abstract}

Keywords: Tourism, pandemic, COVID-19, economy, people's lives.

\section{Introducción}


Un virus es una cápsula inerte que encierra material genético, DNA o RNA; la enfermedad conocida como COVID-19 es ocasionada por el virus SARS-CoV2, causante del síndrome agudo respiratorio severo (UNIVERSIDAD NACIONAL AUTONOMA DE MEXICO, 2020).

El COVID-19 es una enfermedad infecciosa que afecta de distintas maneras, dependiendo de las condiciones de salud de cada persona; la mayoría de las personas que se contagian presentan fiebre, tos seca, cansancio, dolor de garganta, diarrea, conjuntivitis, dolor de cabeza, pérdida del olfato o del gusto y erupciones cutáneas o pérdida del color en los dedos de las manos o de los pies. Los síntomas graves consisten en dificultad para respirar o sensación de falta de aire, dolor o presión en el pecho e incapacidad para hablar o moverse.

De acuerdo con información oficial de la Organización de las Naciones Unidas (ONU), el virus del COVID-19 se transmite principalmente entre personas a través del contacto y de gotículas que salen, al toser, hablar o estornudar, de la nariz o la boca de una persona infectada, por ello es importante mantenerse a más de un metro de distancia para evitar contagios.

El 30 de enero de 2020, el director general de la Organización Mundial de la Salud (OMS) declaró el brote de COVID-19 como emergencia para la salud pública de importancia internacional y promulgó un conjunto de recomendaciones temporales. La OMS no realizó recomendación alguna para restringir a los viajes o al comercio, basándose en la información disponible en el momento. La recomendación general para detener la ola de contagios consistió en detener la movilización de personas mediante el confinamiento en casa y en la práctica de mantener distancia no menor de un metro entre las personas de todas las edades; las autoridades sanitarias y gubernamentales adoptaron medidas para limitar al máximo la propagación de la enfermedad, entre ellas la cuarentena y el aislamiento (Ribot Reyes VC, 2020).

La pretensión de este artículo es comprender y analizar el impacto que el desplazamiento masivo de personas por razones de turismo ha tenido en la propagación del COVID-19, y el peso de la economía contra el deber superior de preservar la vida de las personas.

\section{Materiales y métodos}

Para identificar los impactos generados por el turismo en la diseminación del COVID-19 se realizó investigación documental con base en revisión de fuentes secundarias. Al revisar la literatura se advierte la falta de estudios previos de investigación sobre los efectos del turismo en la diseminación de la pandemia, encontrando una vasta gama de material en el sentido adverso, es decir, se extrae $\mathrm{n}$ de la idea del planteamiento 
que se hace, enfocándose estrictamente en los efectos que el COVID-19 ha generado en el desarrollo de la actividad turística, tanto en su sentido económico como social e inclusive, en el ámbito de equidad de género.

\section{Planteamiento del problema.}

Los efectos financieros derivados del aislamiento, en algunos países obligatorio y punitivo, como medio para detener el crecimiento de la pandemia, no se hicieron esperar. La crisis económica mundial por la interrupción de las cadenas de producción y la pérdida de empleos inició un crecimiento exponencial que de acuerdo al informe Perspectivas económicas del Banco Mundial (BM), sería la peor recesión desde la Segunda Guerra Mundial, y la primera vez desde 1870 en que tantas economías experimentarían una disminución del producto per cápita (Grupo Banco Mundial, 2020).

De todos los sectores económicos, el turismo es, sin lugar a dudas, el más golpeado por la pandemia covid-19; sus pérdidas son devastadoras ya que es el medio de subsistencia de millones de personas y, de acuerdo con lo que señala la Organización Mundial del Turismo (OMT), es el tercer sector más importante de la economía mundial en materia de exportaciones; representa más del 20\% del PIB de algunos países, mientras que para México representa el $8 \%$ y es también uno de los sectores con mayor índice de empleabilidad al generar 4.4 millones de empleos directos y más de 6 millones de empleos indirectos (Arriaga \& González, 2019).

La industria aeronáutica se encontraba en un muy buen momento antes del inicio de la crisis del COVID-19; con el cierre de fronteras a nivel mundial la situación empeoró en cuestión de días y en una semana el espacio aéreo se podría decir que estaba prácticamente vacío, solo se realizaban vuelos de repatriación o de suministro de material sanitario. Se están experimentando muchos cambios y adaptaciones como la desinfección frecuente de las aeronaves, controles sanitarios y el uso obligatorio de las mascarillas. Todo esto con el objetivo de poder retomar la actividad garantizando la seguridad en todo momento tanto para los pasajeros como de la tripulación (Bandera Aguilar, 2020).

Desde el inicio de la pandemia se visualizó que el desplazamiento de personas por vía aérea de un país a otro impulsaría en gran medida la transmisión de la infección, prueba de ello es la suspensión global de las actividades aéreas en el primer trimestre de 2020 debido a que muchos países cerraron sus fronteras e incluso algunos llegaron al punto de confinamiento obligatorio para todos sus habitantes, so pena de apercibimientos y la aplicación de multas sin llegar a penas corporales. Estados Unidos y los países que integran la comunidad europea fueron los primeros en emitir restricciones de viaje, enfocados en proteger la salud de sus habitantes. 
Es evidente que hay países que tienen claro que la concentración masiva de personas no abona al terreno para la disminución y en su caso, erradicación del virus; como lo demuestran las restricciones de conectividad aérea.

Al cerrarse las fronteras y los hoteles y reducirse drásticamente los viajes en avión, en los cinco primeros meses de 2020 las llegadas de turistas internacionales disminuyeron un 56\% y se perdieron 320.000 millones de dólares en exportaciones del turismo. (Organización Mundial del Turismo , 2020). Los efectos devastadores no solo disminuyeron sino sufrieron un incremento al registrar en enero de 2021 una caída del $87 \%$ del número de turistas internacionales en 2021, según cifras oficiales de la OMT (Organización Mundial del Turismo, 2020). Se debe agregar que las predicciones del sector son inciertas ya que el comportamiento errático de los rebrotes no garantiza que se puedan reactivar las operaciones con itinerarios programados, sobre todo ante la incertidumbre de enfrentarse a algo que es desconocido y que ya ha presentado mutaciones que ralentizan el avance de la ciencia para la creación de una vacuna definitiva o, al menos, medicamentos con un índice elevado de confiabilidad para la recuperación del paciente.

Como se mencionó anteriormente, el virus del COVID-19 se transmite principalmente entre personas a través del contacto y de gotículas que salen, al toser, hablar o estornudar, de la nariz o la boca de una persona infectada; entonces, permitir el desplazamiento masivo de personas y la concentración de grupos numerosos en playas, parques temáticos, zonas arqueológicas, restaurantes y todos aquellos atractivos que motivan el desplazamiento se convierte en uno de los medios más poderosos para la propagación del virus. La evidencia actual sugiere que la diseminación de la pandemia alrededor del mundo se dio por el desplazamiento de personas que viajaron de un país a otro cuando ya el virus había traspasado la frontera de su país de origen, creando un efecto multiplicador que, a juicio de la OMS ha afectado a más de 183 millones de personas en el mundo y estima que el número real de muertes por coronavirus es 2 o 3 veces superior a los 3.4 millones de fallecimientos notificados actualmente por la agencia (Organización Mundial de la Salud, 2021).

Nueve meses después del inicio de la pandemia las cifras alcanzaron el millón de muertes, sin embargo solo tomó un lapso de tres meses para llegar al segundo millón de fallecidos por COVID-19. Haciendo un comparativo entre las cifras de contagios y fallecimientos en noviembre de 2020 y enero de 2021 se evidencia una alza significativa en el número de casos positivos, manteniendo la curva de contagios con un amplio margen de crecimiento; se infiere entonces que esta alza es motivada por la apertura de restricciones de viaje para la temporada vacacional de fin de año y por la relajación de las medidas sanitarias, de manera que este panorama conduce a plantear la tesis de la contribución que el turismo ha hecho para la propagación de la pandemia y si al declararlo como actividad esencial tendría como contrapeso el efecto negativo de la dispersión aún mayor de esta, aunado a que, ante el escenario de ensayo y error, las consecuencias de una reactivación total de la 
actividad turística generaría a mediano plazo efectos que pudieran ser devastadores en la pérdida de vidas humanas.

Gráfica 1: Contagios de coronavirus en el mundo, noviembre y diciembre de 2020 y enero de 2021

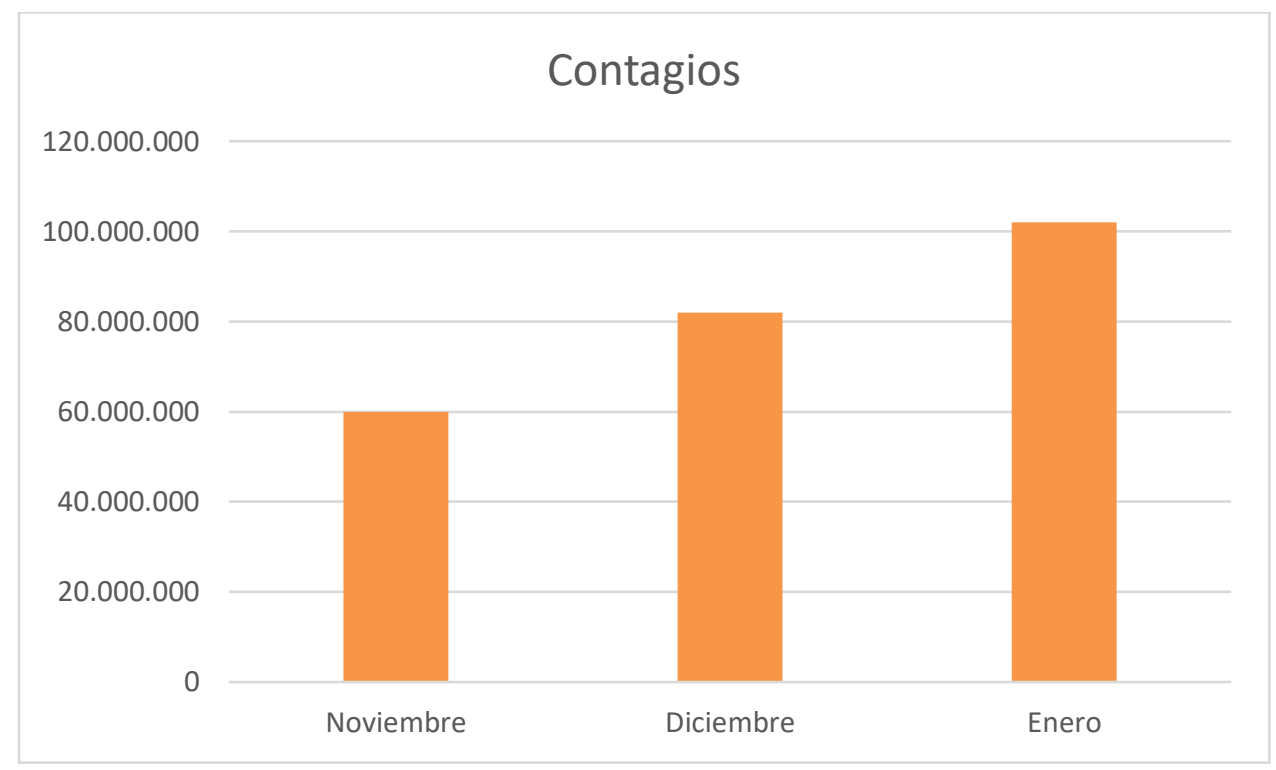

Fuente: Elaboración propia con base en datos de autoridades nacionales y con informes de la OMS.

Gráfica 2: Muertes por coronavirus en el mundo, noviembre y diciembre de 2020 y enero de 2021

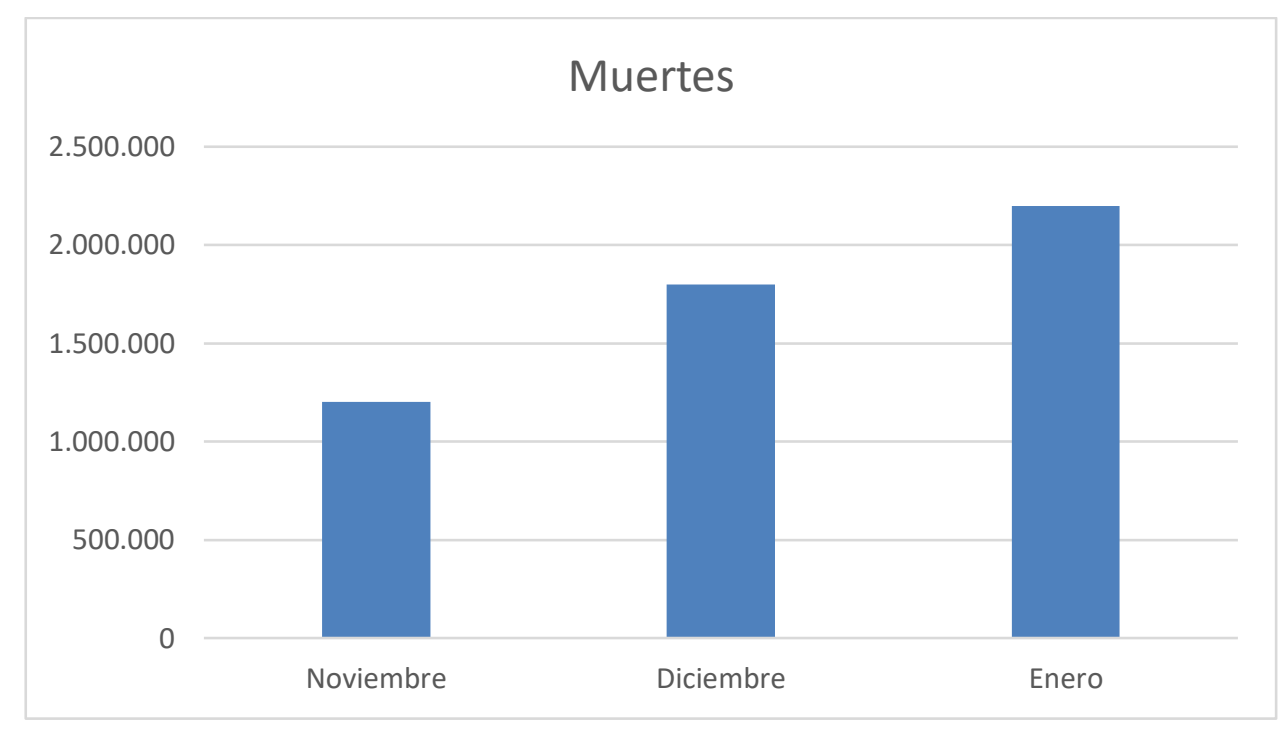

Fuente: Elaboración propia con base en datos de autoridades nacionales y con informes de la OMS. 
Luego de la implementación de un ambicioso programa de vacunación, a finales de febrero de 2021 India registró un descenso en la aparición de nuevos casos y en sus tasas de mortalidad; esto llevó a un relajamiento en el distanciamiento social y en la portación de mascarillas, como se aprecia en diversas imágenes que han circulado en medios de comunicación mostrando grandes concentraciones de personas en el "Kumbh Mela" ${ }^{1}$ así como en eventos políticos de carácter electoral. En abril del mismo año, una segunda ola de coronavirus causó devastadores estragos en Uttar Pradesh, el estado más poblado de India, llegando a reportar hasta 350,000 casos por dìa y más de dos mil defunciones. (Rannard, 2021). Con un total de 851.620 infecciones y 9.830 muertes desde que comenzó la pandemia el año pasado, Uttar Pradesh no lo había hecho tan mal durante la primera ola que devastó a muchos otros estados indios (BBC , 2021), sin embargo, hoy ya se le considera el epicentro mundial de la pandemia del coronavirus (EFE, 2021) y una amenaza global si no cierran sus fronteras, como en su momento debió hacerlo Wunham, China. El caso de India es un claro ejemplo de que solamente evitando las grandes concentraciones se podrá contribuir con el proceso de control y, esperanzadoramente de erradicación, de esta pandemia que ha llevado a la humanidad a una catástrofe de salud pública.

\section{Resultados}

La perspectiva económica nos impele a buscar los medios para la reactivación de servicios de transportación, hospedaje y restauración en afán de dar certeza de supervivencia a la cadena productiva del turismo, sin embargo no se observa un desempeño de las organizaciones públicas y privadas acordes al tamaño y alcances de la contingencia, por lo que se torna necesario analizar la capacidad de respuesta de las organizaciones para enfrentar eventos inesperados y presentar soluciones creativas que conduzcan a un perfecto equilibrio entre la misión de la empresa y el respeto a la vida humana.

Se plantea entonces la disyuntiva de elegir entre la reactivación económica o la preservación de la salud e incluso la vida de quienes se contagian de este virus que ya ha demostrado su grado de fatalidad. Esta crisis humanitaria se suma a las repercusiones de la recesión económica mundial ocasionada por la pandemia y que podría ser esta última, el resultado del manejo inadecuado de una contingencia sorpresiva que las organizaciones públicas y privadas no supieron manejar.

Por otro lado, también está el costo que la atención médica significa para los gobiernos de cada país y que, bajo las condiciones de restricciones de movilidad a viajes puramente esenciales, podría significar una oportunidad

\footnotetext{
${ }^{1}$ Reunión religiosa celebrada cuatro veces cada doce años, en la que se congrega el mayor número de peregrinos del mundo. Estos se sumergen o se bañan en aguas de ríos sagrados para lavarse de sus pecados y librarse así del ciclo continuo de reencarnaciones. Inscrito en 2017 en la lista representativa del Patrimonio Cultural Inmaterial de la Humanidad (UNESCO, 2017).
} 
de contribuir económicamente con los proyectos de investigación científica para lograr la vacuna definitiva o bien para ampliar el universo de la población con acceso a la inoculación.

\section{Discusión}

Este panorama centra al turismo en la disyuntiva de la necesidad y la contingencia. Por una parte, se encuentra la necesidad de mantener activos los sistemas económicos como medio de sustento de millones de personas, sin dejar de mencionar la necesidad individual de ocio y esparcimiento que por sí misma tiene un peso significativo y, por otra parte, el deber superior de privilegiar la vida humana por encima de todo. Sin movimiento de personas el riesgo de contagio de covid-19 disminuye drásticamente; sin desplazamiento de personas no hay turismo y sin turismo no hay ingresos.

Desde el inicio de la pandemia se buscó frenar el desplazamiento de personas como primer recurso para detener la frecuencia de contagios, sin embargo, no todos los actores del turismo coinciden con esta premisa. Maribel Rodríguez, vicepresidenta senior y CEO del Consejo Mundial de Viajes y Turismo (WTTC), World Travel \& Tourism Council por sus siglas en inglés, plantea que "hay que eliminar las barreras y entender que las cuarentenas no sirven", mencionando a la vez que "la única manera de salir (de la crisis) es asegurando que el sector público y privado estén alineados, por lo que es urgente eliminar las barreras a los viajes y establecer un marco común de colaboración” (movilidad", 2021).

En la siguiente gráfica se observa el número de pérdidas humanas ocasionadas por el COVID-19, resaltando México dentro de los primeros cinco países con mayor número de casos. Es importante resaltar que los países con más alto índice de contagios son también los que ocupan los primeros lugares dentro del ranking de destinos turísticos favoritos en el mundo.

Gráfica 3: Muertes por coronavirus en el mundo, (Del inicio de la pandemia al 25 de junio de 2021 


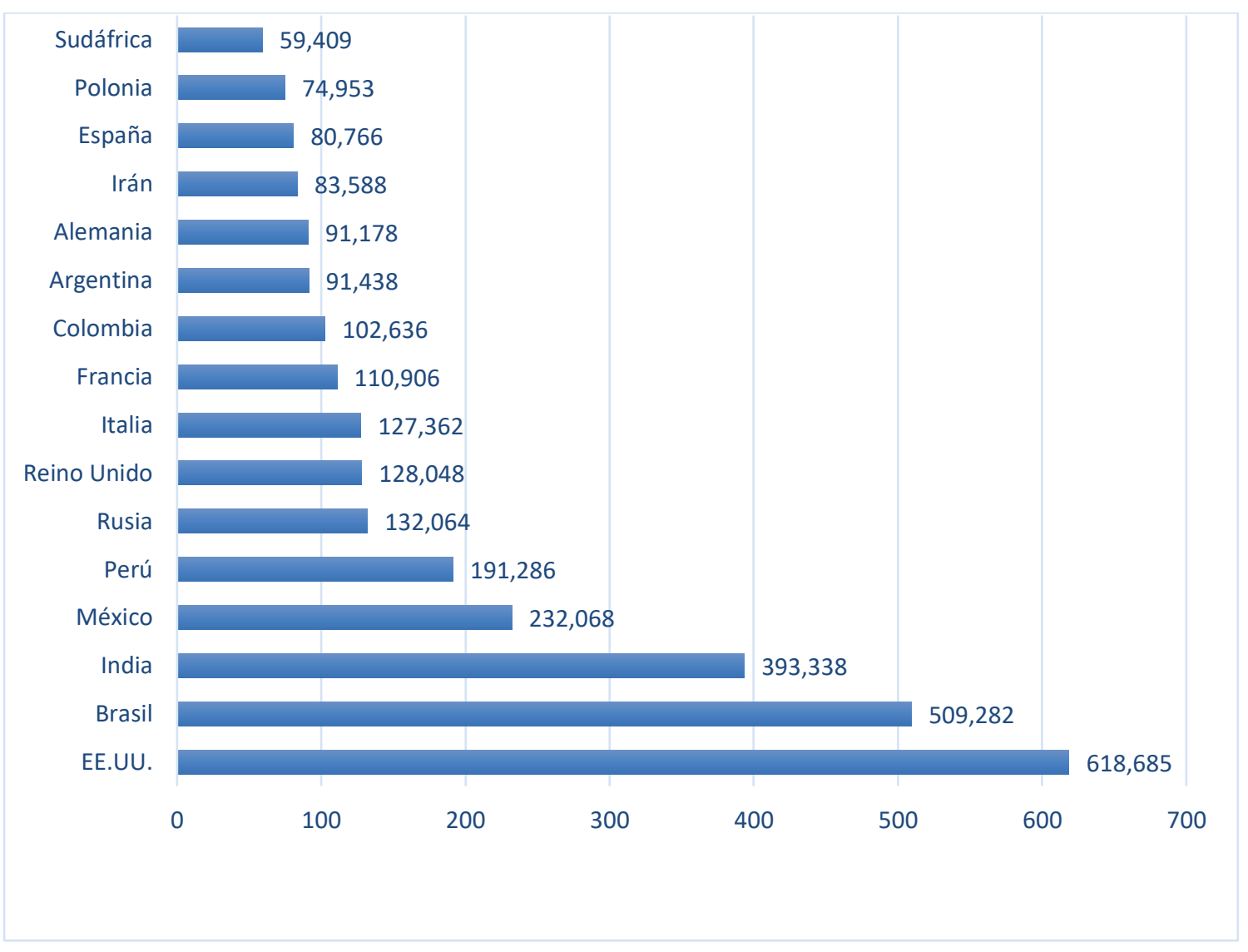

Fuente: Elaboración propia con base en datos de ( (Jhons Hopkins University \& Medicine, 2021). Nota: Los datos corresponden al periodo que comprende del inicio de la pandemia al 25 de junio de 2021.

En el caso de México, el 1 de febrero de 2020, el secretario de Turismo, Miguel Torruco Marqués, solicitó a las Secretarías de Salud y Economía emitir una declaratoria para considerar al turismo como actividad esencial, bajo el argumento del impacto que tiene en la economía nacional, haciendo énfasis "en evitar que la pandemia del SARS-CoV-2 genere mayores pérdidas económicas en el sector turístico" (www.gob.mx, 2021). Declarar al turismo como actividad esencial generaría beneficios de gran relevancia para la recuperación económica del sector, por lo contrario está la otra cara de la moneda, donde a través de las grandes movilizaciones se continúa incrementando el número de contagios, ocasionados principalmente por los portadores asintomáticos que en gran medida desconocen su condición y, habría que mencionar también, la resistencia de muchas personas a usar cubrebocas, guardar distancia y tomar las medidas necesarias de aseo continuó de manos. Javier Ruiz Hermoso, director de la Escuela de Turismo y Gastronomía de la Universidad Anáhuac Puebla menciona que El Consejo Mundial de Viajes y Turismo (WTTC por sus siglas en inglés) analizó 90 crisis de alto impacto sufridas entre 2001 y 2018, identificando que el tiempo de recuperación se ha reducido en promedio de 28 a 10 
meses. En el caso específico de epidemias el tiempo promedio ha sido de 19.4 meses, por ello se considera que mantener las restricciones de viaje puede generar impactos positivos de mayor peso para cortar la cadena de contagios y disminuir la pérdida de vidas que ninguna economía puede resarcir.

\section{Conclusión}

Aun cuando se implementen esquemas masivos de vacunación, no existen pruebas de que una persona vacunada no contraiga y a su vez contagie el virus, por lo que volvemos al escenario de ensayo y error donde las circunstancias y la investigación científica darán la respuesta a las interrogantes y por consiguiente tanto los países emisores como los receptores de turismo deberán implementar restricciones y protocolos que permitan una reactivación de la actividad turística poniendo en primer lugar la salud y la vida de las personas. Lo anterior permite considerar que la prolongación del confinamiento acercará a las economías a una recuperación más próxima, y por el contrario, una inmediata aceleración de desplazamientos no esenciales hará mucho más lenta la recuperación, elevará el costo de atención en los servicios públicos de salud y un mayor número de vidas se perderán.

Superar esta pandemia requiere no solamente de estudios científicos sino de la disposición y disciplina de toda la población mundial para aplicar las medidas que las organizaciones de salud recomiendan, haciendo énfasis en la sana distancia y el uso de cubrebocas especiales que no permitan el esparcimiento de partículas al toser y estornudar. Algunas empresas del sector turístico están conscientes de la importancia que reviste evitar la concentración de grupos de personas en la lucha contra esta pandemia de proporciones inesperadas. A partir de marzo de 2020, las navieras se vieron forzadas a implementar estrictos protocolos de salud para continuar con los viajes ya iniciados, llegando incluso a denegar el embarque a los pasajeros que hayan viajado desde, hacia o a través de China y Europa en los 15 días previos al embarque. Estos actos hablan del compromiso con la preservación de la vida, por encima de las enormes pérdidas económicas que ello significa. El 20 de mayo de 2020, Alberto Muñoz, vicepresidente de Royal Caribbean Latinoamérica anunció la suspensión de navegaciones, efectivo de inmediato y hasta el 31 de julio. (Caribbean, Royal, 2020). Como parte de las medidas para enfrentar la pandemia, no solo detuvieron la navegación de sus cruceros, sino que conformaron un equipo de trabajo con médicos epidemiólogos y expertos en bioseguridad, además de implementar un nuevo programa de políticas de reembolsos, reprogramaciones y cancelaciones con una balanza de beneficios inclinada en favor de los clientes. Estas medidas que para muchos resultaron inconvenientes son un ejemplo de la capacidad de reacción ante un imprevisto en el que no se tiene un control directo por parte de la organización. 
Por otra parte, es necesario que las empresas del sector inicien un plan de acciones que permitan abrir brecha en nuevos modelos de turismo bajo ejes rectores que ponderen la salud de las personas, como en su momento los trágicos eventos del 11 de septiembre cambiaron la forma de hacer turismo, creando un nuevo orden mundial en el que el turista se vio forzado a respetar las restricciones que en los últimos años permitieron realizar viajes con mayor tranquilidad. En esta nueva era del turismo solo sobrevivirán las empresas que desarrollen productos innovadores con procedimientos estratégicos que garanticen la correcta operación de la empresa y la seguridad de sus clientes, manteniendo ventajas competitivas que permitan enfrentarse a los cambios ambientales en escenarios evolutivos, pero a la vez inciertos.

\section{Bibliografía}

(s.f.).

La Agencia de Viajes México. (30 de Junio de 2021). La desigual vacunación impacta en la reactivación turística. Obtenido de La Agencia de Viajes México: https://mexico.ladevi.info/reactivacionturistica/la-desigual-vacunacion-impacta-la-reactivacion-turistica-n31944

Caribbean, Royal. (20 de Mayo de 2020). Mensaje Especial. Obtenido de www.facebook.com: https://www.facebook.com/watch/?v=239947507278802

Arriaga, R., \& González, C. (2019). La Contribución de la Cultura y el Turismo al Empleo en México: Una estimación de los Multiplicadores Tipo I y Tipo II. Análisis Económico, 35-64.

Bandera Aguilar, Y. (Julio de 2020). El impacto del COVID-19 en el sector aeronáutico español. Obtenido de Universidad Autónoma de Barcelona: https://ddd.uab.cat/pub/tfg/2020/tfg_287360/TFG_Yainet_Bandera_Aguilar.pdf

BBC . (2021 de abril de 2021). www.bbc.com. Obtenido de mundo/noticias: https://www.bbc.com/mundo/noticias-internacional-56818586

EFE. (30 de abril de 2021). www.elconfidencial.com. Obtenido de https://www.elconfidencial.com/mundo/2021-04-30/india-se-convierte-en-el-epicentro-de-lapandemia-y-registra-un-nuevo-maximo-historico_3057719/

Grupo Banco Mundial. (2020). bancomundial.org. Obtenido de Perspectivas Económicas Mundiales: https://www.bancomundial.org/es/publication/global-economic-prospects

http://www.scielo.org.mx/scielo.php?script=sci_arttext\&pid=S2448-66552019000200035. (2019). $\quad L a$ Contribución de la Cultura y el Turismo al Empleo en México: Una estimación de los Multiplicadores Tipo I y Tipo II.

https://es.euronews.com/2021/03/17/en-que-consiste-el-pase-verde-el-pasaporte-de-vacunacion-presentadopor-la-comision-europea. (2021). ¿En qué consiste el pasaporte verde, el pasaporte de vacunación presentado por la Comisión Europea? Bruselas. 
https://es.statista.com/estadisticas/1095779/numero-de-muertes-causadas-por-el-coronavirus-de-wuhan-porpais/. (2021). statista.com.

https://www.e-unwto.org/doi/abs/10.18111/wtobarometeresp.2020.18.1.7. (2020). Barómetro OMT del Turismo Mundial y anexo estadístico. Haya.

Jhons Hopkins University \& Medicine. (25 de junio de 2021). Jhons Hopkins University. Obtenido de Coronavirus Resource Center: https://coronavirus.jhu.edu/region

movilidad", W. ". (24 de junio de 2021). La Agencia de Viajes México. Obtenido de mexico.ladevi.info: https://mexico.ladevi.info/wttc/wttc-el-sector-privado-no-va-aguantar-mas-movilidad-n31815

Organización Mundial del Turismo . (4 de junio de 2020). Barómetro OMT del Turismo Mundial y anexo estadístico. Obtenido de eLibrary: https://doi.org/10.18111/wtobarometeresp

Organización Mundial del Turismo. (diciembre de 2020). eLibrary. Obtenido de Barómetro OMT del Turismo $\begin{array}{llll}\text { Mundial } & \text { y } & \text { anexo } & \text { estadístico: }\end{array}$ unwto.org/doi/abs/10.18111/wtobarometeresp.2020.18.1.7

Organización Mundial del Turismo. (2021). Glosario de términos de turismo. Obtenido de Organización Mundial del Turismo: https://www.unwto.org/es/glosario-terminos-turisticos

Organización Mundial de la Salud. (2021). World Health Statistics 2021. Obtenido de Monitoring Health for the SDGs, sustainable development goals: https://cdn.who.int/media/docs/default-source/ghodocuments/world-health-statistic-reports/2021/whs-2021_20may.pdf?sfvrsn=55c7c6f2_3

Rannard, G. (1 de mayo de 2021). www.bbc.com. Obtenido de Coronavirus en India: los desesperados mensajes en redes para salvar a pacientes de covid-19 en el epicentro de la pandemia: https://www.bbc.com/mundo/noticias-internacional-56929261

Ribot Reyes VC, C. P. (15 de abril de 2020). Efectos de la COVID-19 en la salud mental de la población. Obtenido de Revista Habanera de Ciencias Médicas: http://www.revhabanera.sld.cu/index.php/rhab/article/view/3307

UNESCO. (2017). Organización de las Nacionaes Unidas para la Educación, la Ciencia y la Cultura. Obtenido de 'Kumbh Mela', Festividad de la Jarra Sagrada: https://ich.unesco.org/es/RL/kumbh-melafestividad-de-la-jarra-sagrada-01258

UNIVERSIDAD NACIONAL AUTONOMA DE MEXICO. (2020). Revistas UNAM. Recuperado el julio de 2021, de El origen de COVID-19: lo que se sabe, lo que se supone y (muy poquito) sobre las teorías de complot: http://www.revistas.unam.mx/index.php/req/article/view/75461/66829

www.gob.mx. (2021). Solicita Miguel Torruco que la industria turística sea declarada actividad esencial. Ciudad de México. 